\title{
HIJOS DE UN DIOS MENOR. LENGUAJE, COMUNICACIÓN Y COLONIALIDAD DEL PODER
}

\author{
Pablo Estévez Hernández \\ Escuela Universitaria de Turismo Iriarte
}

\section{RESUMEN}

Este artículo propone una lectura alegórica del film de 1986 Hijos de un dios menor. Centrándose en el papel que juega el lenguaje, se analizan los patrones jerárquicos que se establecen en las relaciones vislumbradas a lo largo del film, comprendiendo un paralelismo con las relaciones coloniales y la colonialidad.

Palabras Clave: lenguaje, lengua de signos, Hijos de un dios menor, colonialidad.

\section{CHILDREN OF A LESSER GOD. LANGUAGE, COMMUNICATION AND COLONIALITY OF POWER}

\section{Abstract}

This paper aims to be an allegorical Reading of the 1986 film Children of a Lesser God. It focuses on the role of language, analyzing the hierarchical patterns stablished in the relationship glimpsed throughout the film, comprehending a parallelism with coloniality and colonial relations.

Keywords: Language, sign language, Children of a Lesser God, Coloniality.

Esa urgencia de poner mundos en relación. El sueño de un lenguaje común.

Mi envidia no es sencilla cuando pienso en los amantes, en su ciega fe, en sus crucifixiones experimentadas. He sońado con irme

a dormir como si entrase en límpidas aguas rodeadas por un nevoso bosque, tan blanco como unas sábanas frías, pensando, ahí dentro me congelaré.

\section{Adrianne Rich}

DOI: http://doi.org/10.25145/j.latente.2018.16.004 


\section{INTRODUCCIÓN}

Algo me perturba al ver Hijos de un dios menor (Randa Haines, 1986), una adaptación de una obra teatral de Mark Medoff. Se ha convertido para mí en una de esas películas que contienen un fondo oculto, que, mientras establecen su narrativa con la normalidad esperada en las representaciones melodramáticas, al tiempo contienen un simbolismo y una estructura que se dirige al inconsciente; al punto donde me dirige es a tomarla como una alegoría de las representaciones derivadas de las relaciones coloniales, del heteropatriarcado y del lenguaje que se articula en estas relaciones. Pero muy poco de Hijos de un dios menor tiene que ver en apariencia con las relaciones coloniales, con la colonialidad del poder o con la subalternidad colonial. Muy poco tiene que ver con la historia, la cultura, el poder. Algo, no obstante, puede decirnos de manera obvia sobre las relaciones heteropatriarcales. Y, no obstante, algo clama a que el guion de Markoff excede la simple historia romántica que se despliega ante el espectador.

La historia narra cómo un profesor con cierto idealismo y visión de cambio entra en una escuela donde debe dar clases a un alumnado sordo. En principio la directiva de la escuela se muestra reacia al idealismo que transpira el personaje interpretado por William Hurt. No obstante, James Leeds (Hurt) logra desarrollar una pedagogía participativa donde el alumnado sordo es instado a «hablar». La división del alumnado al principio de la clase sobre la utilización del habla es significativo: el perfil tradicionalmente marginal es el que se resiste, mientras el grupo popular ve la iniciativa con entusiasmo. No obstante, poco a poco, la participación aumenta. La trama se complica en lo que ya parece una estereotipada historia donde la figura siempre paternal del profesor muestra la capacidad de superación de los límites de sus alumnos. Entonces es cuando ella aparece. Interpretada magistralmente por Marlee Matlin, el personaje femenino tiene una historia complicada con la directiva del colegio y con su propia familia. Siquiera así, trabaja como empleada de mantenimiento en el centro. El personaje de Hurt se enamora de ella y pronto establecen una relación marcada, desde el primer momento, por la resistencia de ella a «hablar». Por lo tanto, toda su comunicación se basa en la lengua de signos.

¿Es posible producir una alegoría del film Hijos de un dios menor que verse sobre la violencia física, simbólica, patriarcal y colonial? ¿Por qué hacerlo ahora, viendo que el film no tiene apenas relevancia en la actualidad sobre estos tópicos? Y ¿acaso no es el film un melodrama sin mayor intencionalidad que la de ofrecer una historia de amor con la prototípica secuencia: él se enamora, ella se resiste, hay algo que los separa, pero finalmente se vence? En ese caso, ¿no estaríamos volviendo de nuevo a la rutina, a redundar en aspectos ya ciertamente deconstruidos desde los film studies y los estudios culturales de diverso fondo? Queda una última complicación: ¿en qué sentido el film nos habla de violencia colonial, cuando su trasfondo es una aislada comunidad de Nueva Inglaterra?

El aspecto prototípico de este film pasaría por alto un estudio con algo de intensidad sobre las relaciones de poder coloniales establecidas si el lenguaje no estuviera situando a los personajes de una manera tan poderosa (Susan Felleman ya ha anticipado este estudio revisando las metáforas de fluidez y la subjetividad 
femenina en el film). En muchos sentidos, Hijos de un dios menor es sencillamente un film sobre las complicaciones de la comunicación, sobre vivir el mundo a través de categorías y sentidos y sobre el poder para jerarquizar a través de ese proceso. Visto de una manera compleja, la película incuba una poderosa reflexión sobre el lenguaje, sobre los lenguajes y su formulación del poder. Por ser una historia compuesta por las relaciones interpersonales de una pareja heterosexual, mucho se puede sacar desde un punto de vista feminista con respecto al papel que juega ese lenguaje y a cómo se articula. Pero también apostaré a que la película, en conjunto, puede funcionar como una penetrante alegoría del lenguaje en las relaciones coloniales. Me imagino que revisitar el film de esta manera implica extraer los elementos melodramáticos y forzarnos a ver más allá de los aspectos parciales como producto cultural estándar. Implica, por tanto, leer sus imágenes con toda sus problemáticas y su fuerza.

\section{LENGUAJE, COLONIALISMO Y COLONIALIDAD DEL PODER}

"Otorgamos una importancia fundamental al fenómeno del lenguaje», dice Frantz Fanon en Piel negra, máscaras blancas. Aquí, el intelectual martinico establece un vínculo teórico con W.E.B. DuBois al recalar en una especie de doble consciencia en el sujeto racializado como negro. Esta doble consciencia está marcada, dice Fanon, por la «aventura colonial». Y sobre esto dice que no hay dudas. La forma en que articula el lenguaje el negro es diferente según estas dos formas de pensar (que también son formas de ser). Por ello, el lenguaje funciona también en el plano del deseo, del poder y de la mimesis. El «francés», el idioma del colonizador, es el que marca la pauta normativa y que permite al sujeto entrar en la zona del ser. Y así, dice Fanon: «El negro antillano será más blanco, es decir, se aproximará más al verdadero hombre, cuanto más haga suya la lengua francesa» ${ }^{1}$.

Fanon está esclareciendo aquí una cuestión básica del colonialismo: su operatividad binómica, la manera de provocar dos pares confrontados en la relación. En este sentido, el colonialismo, el discurso del colonialismo, recrea la división de dos conglomerados poblacionales que también son dos mundos culturales, dos cosmovisiones, pero una prima sobre la otra. En este sentido, el colonialismo operó como una expresión de una articulación de la diferencia que usaba diferentes patrones de clasificación. Como bien indica Aníbal Quijano: «Se trata siempre de una articulación estructural entre elementos históricamente heterogéneos. Es decir, que provienen de historias específicas y de espacios-tiempos distintos y distantes entre sí, que de ese modo tienen formas y caracteres no sólo diferentes, sino discontinuos, incoherentes y aún conflictivos entre sí, en cada momento y en el largo tiempo» (p. 347). Por eso, se puede definir la colonialidad como «uno de los elementos constitutivos y específicos del patrón mundial de poder capitalista. Se funda en la imposición de una clasificación racial/étnica de la población del mundo como piedra angular de

${ }^{1}$ Fanon, Frantz (2009): Piel negra, máscaras blancas, Akal, Madrid, p. 490. 
dicho patrón de poder y opera en cada uno de los planos, ámbitos y dimensiones, materiales y subjetivas, de la existencia social cotidiana y a escala societal $»^{2}$.

El lenguaje, en el sentido en el cual lo estudia Fanon, supone un factor clave del establecimiento de la diferencia colonial, uno de los fundamentos que definen la superioridad de los colonizadores, al tiempo que mide la inferioridad de los colonizados ${ }^{3}$. Fanon muestra que la relación entre el colonizado y el colonizador es una lucha por el reconocimiento, donde el lenguaje se instrumentaliza en una pugna por la visibilidad ${ }^{4}$. En el universo fílmico de Hijos de un dios menor, podemos establecer que la norma la marca no el inglés como idioma, pero sí el lenguaje hablado, articulado por sonidos audibles por una mayoría. Aunque la sociedad que da contexto al film se rige por la norma visual, estipulada en la comunicación de lo que "es visto" y queda "por escrito", un estilo de gestión de las relaciones sociales que viene gestándose desde la Edad Media, pareciera que en el microcosmos que incluye la relación (no sólo pedagógica) entre los sordos y la más amplia comunidad se rige por un corte no visual sino audible, que marca los parámetros de lo aceptado en un proceso comunicativo estándar:

${ }^{2}$ Quijano, Aníbal (2000): «Colonialidad del poder y clasificación social», Journal of world-systems research, VI, 2, summer/fall, pp. 342-386, p. 342.

${ }_{3}$ En la Guinea colonial gobernada por los españoles se intentaba inculcar la lengua española. Algo mágico ocurría con el idioma en este sentido: los problemas de disparidad nacional españoles se disipan para establecer dos entes claros: los del binomio colonial. Un libro es especialmente importante aquí: Manuel Castillo BARril (1966): La influencia de las lenguas nativas en el español de la Guinea Ecuatorial, CSIC, Madrid. Aquí se mostraban estos apuntes pertinentes: «Pese a la influencia que pudo haber ejercido por las variedades regionales que allí viven, pues, a pesar de ello, en la Guinea o en la colonia de entonces, el habla particular o regional de los peninsulares se unifica en el castellano» (p. 15). El estadio en el que hace su análisis del idioma español en la colonia no es de un variado rango de dialectos tribales, sino uno de «bilingüismo», aunque arguye que «el bilingüismo, y, por analogía, el polilingüismo, es un uno de los problemas más acuciantes y complejos [...] no sólo en efectos psicológicos, sino por las políticas sociales que implican» (p. 10). Desde esta mirada, claro está, cualquier forma de polilingüismo es complicada, porque supone no aceptar la superioridad y la dominación española (o la de cualquier entidad colonizadora).

${ }^{4}$ Florian Coulmas dice lo siguiente con respecto a la instrumentalización de las lenguas, citado en Mignolo, Walerter D. (2002): Historias locales/diseños globales. Colonialidad, conocimientos subalternos y pensamiento fronterizo, Akal, Madrid: «Las lenguas se han utilizado siempre para establecer o reclamar una esfera de influencia. Se han impuesto como lenguas imperiales sobre grupos étnicos dominados, por cualquiera que tuviera el poder de hacerlo. Muy a menudo se ha considerado un código uniforme como una cuestión de comodidad administrativa para gobernar un país del imperio. Sin embargo, la ideologización del lenguaje es una cuestión diferente; y si un grupo dominante puede emplear la lengua como símbolo de la nacionalidad, los grupos dominados pueden, por supuesto, aplicar la misma lógica y plantear reivindicaciones políticas basadas en su identidad lingüística. Así, mientras se puede decir que la idea de una lengua nacional y de su instrumentalización política funciona como fuerza cohesiva, también es cierto lo contrario. La lengua puede ser una fuerza disgregadora como cualquier otra seña de identidad cultural, y está claro que la lengua-ideología nacional ha originado conflictos intracomunales y, en cierto sentido, ha creado en muchos países minorías que han llegado a constituirse como Estados en los tiempos modernos» (p. 296). 
Una sociedad en la cual el principal conducto de la autoridad era el oído, [...] empezó a convertirse en una sociedad en la cual imperaba el receptor de luz: el ojo. La palabra auditoría (cuya raíz es la misma que la de audible y auditivo), que era el nombre del examen consistente en escuchar a los testimonios, emprendió el extraño viaje que la llevaría a significar, casi sin excepción, examinar mediante la lectura en silencio absoluto5.

Por otro lado, la lengua de signos, en la que sólo unos pocos miembros de la comunidad de Nueva Inglaterra están instruidos, supone un lenguaje fuera de la norma, claramente subalterno en este contexto. Hacer hablar a los sujetos sordos en un aula dominada por estos sujetos supone, en este sentido, una forma de intrusión, de hacerles saber el poder normativo del lenguaje «metropolitano». La lengua de signos, contextualizado aquí, es un lenguaje «impuro».

Una de las principales características de la opresión imperial es el control sobre el lenguaje. El sistema de la educación imperial instala una versión «estándar» del lenguaje metropolitano como la norma y marginalizada las «variantes como impurezas», [...]. El lenguaje se convierte el médium por el cual una jerarquía estructural de poder es perpetuada y el medio por el cual las concepciones de «verdad», «orden» y «realidad» son establecidas. Tal poder es rechazado con la emergencia de una efectiva voz post-colonial ${ }^{6}$.

Al tiempo, el lenguaje, que puede ser aprendido, sirve para disponer de movilidad en este sentido, o al menos para aspirar a la mimesis de la Modernidad. En el contexto del film que estamos analizando, aunque sabemos que los sordos nunca podrán escuchar las palabras que pronuncian, el pronunciarlas en sonidos audibles les permite mayores dotes, no sólo comunicativas, sino sociales. De alguna manera entran en el universo social normativo. Pero ¿̇acaso no es obvio que, como el sujeto colonizado que copia el acento y el vestir del colonizador, la articulación problemática de los sujetos sordos de la película remite a una suerte de parodia sobre el lenguaje hablado «natural»? En cualquier caso, su utilización tiene refuerzos positivos; y al cambiar su disposición y uno de los factores clave de su forma de comunicar, también podemos decir que cambia su manera de «entender el mundo». Cambia su mente porque de alguna manera se llega a colonizar la misma. Como dijo Ngũgĩ wa Thiong'o:

La dominación del lenguaje de un pueblo por los lenguajes de las naciones colonizadoras fue crucial para la dominación del universo mental del colonizado7.

5 Crosby, Alfred W. (1998): La medida de la realidad. La cuantificación y la sociedad occidental 1250-1600, Crítica, Barcelona, p. 114.

${ }^{6}$ Ashcroft, Bill, Griffith, Gareth y Tiffin, Hellen (1989): The Empire writes back: theory and practice in post-colonial literatures, Routledge, London, p. 7.

7 Thiongó, Ngũgĩ wa (1986): Decolonising the Mind. The Politics of Language in African Literature, James Currey Ltd., London, p. 16. 
El lenguaje es un campo de lucha; se establece por relaciones de poder entre quienes imponen un lenguaje y quien está subyugado y obligado a hablarlo, leerlo y escribirlo. Este punto nos remite a ver el papel de James Leed en el film como algo más que un profesor benevolente que busca integrar a sus alumnos/as. Igualmente, la resistencia de Sarah Norman, el personaje de Marlee Matlin, supone un esfuerzo no por descolonizarse, sino en primera instancia por evadir la exigencia normativa empujada contra ella. Alegóricamente, ella lucha contra la colonización y contra una colonialidad que la oprime desde una multitud de ejes. No obstante, ese imperativo se le presenta en cientos de ocasiones a lo largo de todo el film. Su resistencia no sólo la lleva a no compartir un espacio comunicativo más amplio, sino que supone su entera marginación social: el rechazo de su familia y su puesto de subalterna en cuanto a su posición laboral. En cierto sentido, su amor por el personaje de Hurt es uno de los primeros visos hacia cierto estatus de aceptabilidad social, pero el introducirse en ese mundo social implica una complicación de la torre que ha edificado como su resistencia. Hay que ver el anverso de esa resistencia en una curiosa y exasperante ansiedad por parte de James por hacer de su pareja un sujeto que enuncia, que habla. Su ansiedad ¿es la de un sueño de normalidad? Visto esto en el contexto colonial:

El lenguaje del colonizador, por contraste, se convierte en una necesidad para aquellos que desean avanzar socialmente y participar en la esfera pública de la colonia. Se evita rápidamente el uso de lenguas locales para favorecer el lenguaje y la lengua colonial, especialmente por aquellos que buscan una movilidad ascendente ${ }^{8}$.

\section{LENGUAJE DE AMOR}

Esa desventaja social no sólo lo es para el sujeto colonizado, también lo es para los poderes coloniales, ya que supone un fracaso de su estrategia. Cuando los sujetos colonizados aprenden el lenguaje del colonizador no sólo se cumple la expectativa de la efectiva dominación de sus mentes, sino que ejerce un papel negativo para la estrategia de control poblacional que se aplica en las colonias. Citado en un texto clave de Gayatri Spivak está esta declaración de Thomas Babington Macaulay, sobre la educación en la India colonial:

Debemos al presente hacer nuestro mejor esfuerzo para formar una clase que pueda ser intérprete entre nosotros y los millones a quienes gobernamos; una clase de personas, indios de sangre y color, pero ingleses en gusto, en opiniones, en moral, y en intelecto. A esa clase podemos dejarle refinar los dialectos vernáculos del país, para enriquecer estos dialectos con términos de ciencia prestados de la nomenclatura

${ }^{8}$ Migge, Bettina y LÉGLise, Isabelle (2007): «Language and colonialism. Applied linguistics in the context of creole communities». En Marlis Hellinger and Anne Pauwels (eds.), Language and Communication: Diversity and Change. Handbook of Applied Linguistics 297-338, Berlin, Mouton de Gruyter, p. 302. 
occidental, y para suministrarles por grados vehículos adecuados para conducir el conocimiento a la gran masa de población?

Incluso una estrategia de hibridismo intencional estaba en la mente de los colonizadores británicos, haciendo énfasis en el lenguaje aprendido y los vernáculos, produciendo una nueva elite local que sirviera los propósitos biopolíticos necesarios para el dominio. Aquí se está haciendo hincapié en un lenguaje que no corresponde sólo con el lenguaje hablado y escrito, ni con el idioma. En el plano del colonialismo se entiende una multitud de dimensiones como una forma de lenguaje que se trasiega entre las sociedades. Edward W. Said definió el orientalismo como un "discurso", siguiendo el planteamiento de Michel Foucault, y lo comprendió como un interface del lenguaje con la realidad. Pero este discurso, el del orientalismo, era una suerte de lenguaje articulado en muchos niveles, de manera sistemática y soportado en relaciones de poder hegemónicas, que situaba el conocimiento y el lenguaje del colonizador en una jerarquía superior a los pueblos que colonizaba. Y ese lenguaje comprende los lenguajes de la gubermentalidad, de la administración occidental, de las epistemes ilustradas, de la formulación política y de la técnica y la tecnología. Digamos que ese lenguaje no es sólo un idioma, es todo un aparataje que incluye sus formas de conocimiento, su organización política, sus instituciones, su planificación espacial, su religión, los nombres de sus lugares, su historia... Ese es el lenguaje común con el que sueña el colonizado. Y así:

«Estadística» sabemos que significa literalmente «la ciencia del Estado». Ya en el cambio de siglo [del siglo XVIII al xIx] el término estaba siendo usado en la India colonial para describir la búsqueda sistemática de datos en temas diversos que podían ser de gran interés para el Estado. Puede que suene extraño, pero podríamos decir que la estadística es un nuevo lenguaje de amor entre gobernantes y gobernados ${ }^{10}$.

Un lenguaje de amor, que también es como todos sabemos, un lenguaje de rencor y odio. Hay que recordar que la lengua hablada quiere ser operada en el film como un lenguaje de amor. Cuando James le propone a Sarah que hable, le pide una «muestra de amor». Lo que le pide es que le diga "te quiero». La resistencia de ella se puede leer como la negación de una relación entre gobernantes y gobernados, proponiendo siempre un espacio neutro donde la dominación no se aplique. Pero este sueño es transitorio. Aunque Leeds maneje a la perfección la lengua de signos, no llega a entender su mundo. Se comporta como un antropólogo colonial que controla a la perfección el lenguaje de los nativos, pero que rehúsa las connotaciones emocionales del objeto que estudia. También fuerza el espacio neutro al hacer notar el estado «elevado» de lo que podría llamarse su «cultura»: el mundo audible. En un

9 Thomas Babington Macaulay citado en Spivak, Gayatri (2003): «Puede hablar lo subalterno?». Revista Colombiana de Antropología, vol. 39, enero-diciembre, pp. 297-364, p. 319.

${ }^{10}$ Chatterjee, Partha (2008): La nación en tiempo heterogéneo y otros estudios subalternos, Siglo XXI, Buenos Aires, p. 40. 
momento dado muestra su predilección por la música, y no duda en situarla como un valor elevado ${ }^{11}$. Él no puede explicarle qué se siente, qué es esa elevación. Con ello provoca una ruptura en la relación, un estado puro de inconmensurabilidad. Todos estos momentos del film han sido enumerados por Susan Felleman:

1) [P]rimer encuentro: «Si me dejas, apuesto a que te puedo enseñar a hablar» 2) segundo encuentro: «Escucha, ¿por qué no engañamos a Franklin y me dejas tener una buena apariencia ante él? 3) primera cita: «¿Sabes? Soy buen profesor. Deberías dejar que te ayude». 4) Después de visitar a la madre de Sarah: «Déjame ayudarte, joder» 5) Después de empezar como amantes, en la cama: «Dios, jamás me podré acercar lo suficiente (la empuja y comienza a decir en signos), di mi nombre. Solo por una vez, di mi nombre (ella niega con la cabeza). Lo siento, lo necesito, estoy $\tan . .^{12}$.

Pero ¿̇entiende él el silencio de ella? Aquí es donde la escena de la piscina es fundamental. No responde únicamente a la dramatización del inicio como pareja, sino que supone un mundo sordo; subacuático y supuestamente inaudible. Entonces él logra, al menos, simular ese mundo, pero luego evita que ella conozca verdaderamente el mundo sonoro cuando en otra escena exige que se le describa la música.

Desde luego, el mundo subacuático de la piscina simboliza el espacio de silencio de Sarah, pero además imprime una metáfora conectada con la representación de la feminidad que establece no sólo un mundo cósmico con la fluidez, lo líquido; sino una escena contenida en la narrativa de las «mujeres que tienen que ser rescatadas». Citado en el texto de Susan Felleman (2006), Klaus Theweleit ${ }^{13}$ dice lo siguiente:

Una y otra vez: la mujer-en-el-agua, la mujer como agua, como un tormentoso, agitado y refrescante océano, una corriente rabiosa; como un cuerpo de agua infinito por donde atraviesan los barcos, con tributarios, piscinas y deltas; mujeres de profundidad tentadora (o peligrosa), como una copa de burbujeantes fluidos corporales; la vagina como ola, como espuma, como un lugar oscuro anillada en crestas pacíficas; el amor como una colisión de dos olas, como un viaje marino, como un lento decaimiento, como un pez capturando una tormenta.

Así se va construyendo la figura femenina misteriosa en la escena de la piscina: como profundidad misteriosa, sensual (y como objeto) y en la profundidad

11 Es más, no solamente queda elevada, sino que hace eco de la máxima de san Isidoro de Sevilla, que marcaría las formas de conocimiento, separando irremediablemente a los sordos de un conocimiento real y completo del mundo: «Sin música no puede haber conocimiento perfecto, porque no hay nada sin ella. Porque incluso el universo se dice que fue creado con cierta armonía de sonidos, y el cielo mismo gira bajo la dirección de la armonía» (Sevilla citado en Crosby, 1998, p. 119).

12 Felleman, Susan (1989): «Fluid Fantasies: Splash and Children of a Lesser God», Camera Obscura 7 (1 19), January, p. 118.

13 Klaus Theweleit citado en Felleman, Susan (1989): «Fluid Fantasies: Splash and Children of a Lesser God», Camera obscura, January, p. 111. 
sorda de un silencio inalcanzable. En este preciso momento, con estas dos relaciones puestas en escena, es cuando la colonialidad del poder intersecta en la relación. Hurt es un hombre blanco profesor y con capacidad de hablar y oír. Ella es una mujer blanca subalterna y sorda.

La primera reacción, espontánea, frente al extranjero es imaginarlo inferior, puesto que es diferente de nosotros: ni siquiera es un hombre o, si lo es, es un bárbaro inferior; si no habla nuestra lengua, es que no habla ninguna, no sabe hablar ${ }^{14}$.

Tzvetan Todorov habla del control hispano de los medios de comunicación durante la conquista de México. Cortés dominaba los medios. El problema para la cultura oral azteca radicaba en que no había una formulación de la llegada de los conquistadores; cuando las dos culturas se encontraron, el resultado fue unas formas de comunicación inconmensurables. Estos eran los ejes comunicativos que resalta Todorov: Conquistadores: de hombres a hombres / Aztecas: de hombres a la tierra-naturaleza (de forma ritual y cíclica). Dicho de otra manera, no compartían la misma cosmovisión: Leeds no puede más que anhelar conocer el mundo de Sarah Norman, pero la piscina, el mundo subacuático, apenas es un simulacro de la convivialidad.

\section{EL SUEÑO DE UN LENGUAJE COMÚN}

En un momento dado de la película Sarah admite esta inconmensurabilidad. Se trata de un deseo que no puede llegar a su objeto, a cumplirse. El mundo del otro es inasequible. Sin embargo, ella no ve un impedimento para la relación de pareja. Aquí parece que hemos llegado a superar viejos patrones del multiculturalismo liberal, de ese deseo obsesivo de comprender al otro enteramente. No obstante, ella cree en la relación pese a la inconmensurabilidad. El punto sería entonces no subyugarse a dejarse dominar por un lenguaje propio, sino buscar un terreno compartido. Como en el precioso poema de Adrienne Rich, lo que buscan es un lenguaje común. $E l$ sueño de un lenguaje común. Podríamos decir aquí que se hace obvio que el lenguaje común es el sistema de signos americano que se usa diariamente para comunicarse.

El sueño de la antropología siempre fue también un sueño de una ecología radical. La separación ontológica que se perpetró marcada por las pautas de la diferencia colonial movilizó a la naturaleza y a los llamados salvajes a un lado de un entramado simbólico que podía ser decodificado. La construcción de una moderna ciencia de la antropología se encargó de ese entramado de signos que los indígenas compartían con la naturaleza. Todorov vuelve a nosotros con el esquema básico que planteó para la inconmensurabilidad comunicativa entre los conquistadores españoles y los aztecas.

${ }_{14}$ Todonov, Tzvetan (2010): La conquista de América. El problema del otro, Siglo XXI, Madrid, p. 94. 
¿Estaríamos aquí forzando la palabra «comunicación» si dijéramos, a partir de eso, que existen dos grandes formas de comunicación, entre el hombre y el hombre, y otra entre el hombre y el mundo, y comprobáramos entonces que los indios cultivan sobre todo la segunda, mientras que los españoles cultivan la primera? Estamos acostumbrados a no concebir la comunicación más que en su aspecto interhumano, pues, como el «mundo» no es un sujeto, el dialogo con él es muy asimétrico ${ }^{15}$.

Tras la Segunda Guerra Mundial creció el interés de manera general en las formas de la comunicación: tanto en los aspectos informáticos y tecnológicos como en el desarrollo de nuevas maneras de interactuar globalmente. Desde luego, lo que estábamos viendo en ese periodo era la creación de un sistema interactivo global novedoso, marcado por las nuevas tecnologías y la carrera espacial, pero asentado sobre las bases del imperio global y la lucha por la independencia política de muchos pueblos. La obsesión por la comunicación empezó a generar expectativas en el ámbito de la biología y la zoología por superar una de las barreras primordiales de los seres humanos con los animales. En este contexto comenzaron los experimentos de aprendizaje de la lengua de signos americana (AMESLAM, la lengua que Sarah Norman prefiere frente al habla) con chimpancés y gorilas (financiados por la $\mathrm{Na}$ tional Geographic Society). Tras varias frustraciones de comunicarse vía el habla en los ańos cuarenta y cincuenta, pronto se reposicionan estos intentos con el uso de la lengua de signos. En 1972 comienzan una serie de proyectos en el zoo de San Francisco relacionados con esta forma de comunicación entre especies. Koko, una de las gorilas en aprender los signos, pronto se ve dotada de una herramienta que capta la gestualidad sintetizando la información y transfiriéndola al lenguaje hablado. Koko es, en este sentido, una cyborg situada entre los ensambles del lenguaje común de la globalización en los años setenta ${ }^{16}$.

¿Qué suponía esta aceptación de una especie inferior como contraparte en el proceso de comunicación? ¿Qué suponía esto en una ciencia moderna marcada por el darwinismo y una jerarquía de especies y razas humanas? Con Koko y otros gorilas se conseguía el sueńo de san Francisco de Asís de "hablar con las bestias» (como hizo notar un artículo del Reader's Digest): se cumplía también el «sueño del etnógrafo de conocer el mundo desde la perspectiva del otro» ${ }^{17}$.

A la vista del film que nos ocupa, este sueño deviene en una pesadilla imperialista. Supone la manera de ir construyendo narrativas frente a la naturaleza y los otros (sordos, mujeres, indígenas...) que se basan en la intrusión. Finalmente es un lenguaje que funciona como los mapas, y sobre todo como los mapas imperiales; se busca llenar los espacios vacíos del conocimiento europeo, convencidos de que van a ser llenados con sus fórmulas de la realidad. Es decir, con sus epistemes. Koko no está en las mismas condiciones de ofrecer su visión porque esta no es más que

${ }^{15}$ Ibíd., p. 84.

${ }^{16}$ Haraway, Donna J. (1989): Primate Visions. Gender, Race and Nature in the World of Modern Science, Routledge, New York, London.

${ }^{17}$ Ibíd., p. 141. 
la carencia expresada en el deseo de conocer de las fuentes económicas, militares y académicas de Occidente. Enseguida, en el plano de Hijos de un dios menor, es donde vemos que la supuesta universalidad de la lengua de signos (particionada por cierto por sistemas nacionales) queda suspendida y entra en una retórica colonial, con James Leeds resituándola en una escala jerárquica. Sin embargo, comprender el silencio era también parte del sueño de lenguaje común generalizado entre la pedagogía con personas sordas. El establecimiento de la lengua de signos suponía sacar esa información fuera de una comunidad de personas desconectadas de la norma. En la jerarquía de Leeds, cabe la pregunta chistosa sobre la ausencia de habla de los chimpancés: «Si son tan listos, por qué no hablan» ${ }^{18}$.

El reclamo final de Donna Haraway (donde se ve la diferencia de acepción del poema de Rich) por una heteroglosia cyborg y feminista puede servir como modelo resolutivo para la película, aunque su propuesta tenga otros parámetros:

No es sólo que la ciencia y la tecnología son medios posibles para una gran satisfacción humana, así como una matriz de complejas dominaciones, sino que la imaginería del cyborg puede sugerir una salida del laberinto de dualismos en el que hemos explicado nuestros cuerpos y nuestras herramientas a nosotras mismas. No se trata del sueño de un lenguaje común, sino de una poderosa e infiel heteroglosia. Es una imaginación de un hablar feminista en lenguas que llenen de miedo a los circuitos de los supersalvadores de la nueva derecha. Significa al mismo tiempo construir y destruir máquinas, identidades, categorías, relaciones, historias del espacio. A pesar de que los dos bailan juntos el baile en espiral, prefiero ser un cyborg que una diosa ${ }^{19}$.

\section{LA DISCUSIÓN Y LA DESCOLONIZACIÓN}

El verdadero momento insoportable del film se ve en una escena de discusión que tiene la pareja. La misma comienza abarcando la siempre constante obsesión del profesor James Leeds: que su novia Sarah acabe hablando por sí misma, que diga "algo». Sin duda, tras esta discusión hay una genealogía de motivos que han desencadenado este desencuentro. Tenemos la cuestión de la sexualidad de Sarah, del historial sexual que ha pasado por el escrutinio de Leeds y que se ha transformado en expresión de sus celos.

Sarah, también, es sexualmente voraz, pero su apetito es asociado en muchas escenas con características amenazantes (léase: castrantes). [...] ella amargamente le describe a James, quien aparentemente cree que es sexualmente ignorante, su historia sexual. Esta consistía prácticamente en prostituirse a sí misma con un número indeterminado de chicos relacionados con su hermana, a una edad muy temprana. «El sexo

${ }_{18}$ Miller, George A. (1985): Lenguaje y habla, Alianza, Madrid, p. 34.

19 Harawy, Donna J. (1995): «Manifiesto cyborg». En, Ciencia, cyborgs y mujeres: la reinvención de la naturaleza, Cátedra, Madrid. 
es algo que puedo hacer tan bien como las chicas que oyen... ¡incluso mejor! dice ella en signos. Cuando, después de describir este «sórdido" pasado a James, ella lo acusa a él de querer desflorar a la "pobre, pequeña, virgen sorda», él reacciona con una violencia reveladora: "¿Te crees que me siento amenazado por eso? ¿Crees que me importa que te hayas follado a todos los chulitos adolescentes? Pues no. ¡Me importa una mierda!» Está claro que Sarah ha tocado un nervio sensible aquí ${ }^{20}$.

Como dice la autora, esos celos vienen por descubrir que Sarah no es una infante o una ignorante sexual, un aspecto que derriba el componente simbólico paternal que establece el personaje de Hurt. Lo curioso de todo esto es ver cómo lo social comienza a yuxtaponerse en lo estrictamente interpersonal y ver cómo el lenguaje se va no sólo entrelazando en la disputa por juzgar la sexualidad del otro, sino que se convierte en un elemento final de la colonialidad, que «marca» de manera extrema en el contexto en el que se mueven los personajes. De ahí la ansiedad de James Leeds.

... el desdén de Sarah por hablar le llena de ansiedad y descreimiento. El lenguaje, que Sarah tiene, en la forma de la lengua de signos, está divorciado del habla [...]. La ansiedad de James no queda paliada por el hecho de que Sarah pueda comunicarse. Su pánico aparente deriva de su inhabilidad (y lo que él cree que es un negativa) a enunciar. Todo esto lleva a la temperamental pelea en la cual él la acusa, entre otras cosas, de contener su voz adrede como una forma de control, demostrando su insistente privilegio de la expresión sonora. Esto sugiere la «envidia» masculina del percibido secreto de la autosuficiencia femenina, discutido vis-a-vis en el discurso psicoanalítico ${ }^{21}$.

Tras resistirse nuevamente a hablar, Sarah le propone a James hacer el amor. Él le responde "que te follen», una aparente negativa que se convierte en agresión. $\mathrm{Su}$ rechazo se convierte en una violación, un acto de repudio sexual teñido de violencia semicontenida que acaba con el fracaso del acto, que queda reducido a un mero intento paródico de alcanzar el clímax sexual en un momento de tensión no resuelta. Tras este acto fallido, ella le dice que ha decidido algo: que nadie volverá a hablar por ella nunca más. Entonces él le pregunta: "¿Cómo te las arreglarás?», a lo que Sarah responde: «Todo el mundo siempre me ha dicho quién soy yo. Y yo les he dejado. [Ellos dicen por mí] Ella quiere, ella piensa... Y muchas veces estaban equivocados y no tenían ni idea de lo que había dicho o quería o pensaba. Ahora no lo van a hacer...». Con este cierre, que James entiende como «lógico», se vuelve a la recurrencia del amor (él si entiende este punto porque la quiere, esa es la lógica que impera en el pensamiento de Leeds), pero ella rápidamente indica que «esto no tiene nada que ver con el amor». No tiene que ver con el amor, tiene que ver sencillamente con la representación, con la apropiación y con una jerarquía. Analógicamente tiene

${ }^{20}$ Felleman, Susan (1989): «Fluid Fantasies: Splash and Children of a Lesser God», Camera Obscura, January, p. 115.

${ }^{21}$ Ibíd., pp. 117-118. 
que ver con el colonialismo y con la representación colonial y heteropatriarcal. Si ella se niega a hablar (la lengua del colonizador), entonces debe ser representada, alguien debe hablar por ella. De esta manera, la explicación de ella se puede leer como un alegato de respeto al colonizado pero sin desechar las posibilidades de la «conexión». Propone hacer un signo dos veces, de manera diferente, haciendo notar las dos posibilidades de la palabra "conectar». En la segunda, que tiene una acepción especial, ella explica que se puede conectar respetando el mundo y la visión de cada uno en una relación. Esto implica dejar de lado la constante intrusión del personaje masculino y de su demanda para hacerla hablar. Implica estar conectados respetando las diferencias.

Ella concluye: «Hasta que no me dejes ser yo, tal como eres tú, no te dejaré entrar en mi silencio». Las dos posiciones que chocan en esta disputa sobre el lenguaje y la resistencia terminan por provocar la angustia en el personaje femenino. Él desoye la demanda, e insiste nuevamente en que la cuestión no se basa en el respeto, sino que vuelve sobre la misma debilidad, pidiéndole que hable. Llegados a este punto, ya sabemos que hablar no es solamente usar las cuerdas vocales y emitir sonidos más o menos articulados en un lenguaje; implica, sencillamente, aceptar la norma. Esa demanda la vemos ahora con mayor dosis de ansiedad, porque, ahora, estamos viendo como espectadores que el personaje masculino está prácticamente perdiendo su único poder, su única posibilidad de establecer una relación como profesor, como hombre, como persona oyente y hablante y como superior a ella. En este momento su demanda por el habla de ella se transforma en violencia y es cuando ella explota (¿se rinde?) y habla; en un momento de una violencia simbólica estremecedora, que se convierte en insoportable con las primeras palabras audibles de Sarah. Como en un encuentro colonial que ya no soporta la estructura discursiva que el colonialismo ha dispuesto en torno a la relación, las palabras de los nativos colonizados y las de Sarah son las mismas. Esas primeras palabras, ejecutadas por primera vez en el lenguaje de colonizador, son audibles pero demasiado dolorosas. Implican una ruptura traumática pero necesaria. Sarah comienza por un grito para evadir la imposición de la demanda de Leeds, y acto seguido podemos entrever que lo que está gritando es: «iNo tengo miedo!».

Esas son también las primeras palabras de todo colonizado cuando articula una respuesta hacia sus dominadores en su propia lengua. Lo mismo podemos ver en la ya clásica película La batalla de Argel (Gillo Pontecorvo, 1966), en una de sus escenas vemos cómo un grupo de mujeres argelinas cambian su vestimenta a una occidental para poder pasar los controles franceses y colocar bombas entre los lugares comunes de los colonos franceses. A su vez, los hombres se aprovechaban de la lectura machista que hacían las fuerzas coloniales de la cultura argelina para vestirse de mujeres y transportar armas. Toda esta inversión dice mucho del lenguaje utilizado. En un momento dado, los argelinos articularon sus primeras palabras en el lenguaje del colonizador. Y este, al ver que pierde el control, responde con una fuerza militar y opresiva inigualable. Pero el momento en el que lo hace, a lo que asistimos desde la aparición del coronel Mathieu en Argelia, corresponde a la pérdida de control e intuimos que los argelinos colonizados ya han ganado la batalla y la guerra por la independencia. 
Cuando Leeds pierde todo el control, entonces dice: «iQuieres que no te tengan lástima! ¡Entonces aprende a leer mis labios y utiliza esa boquita tuya para algo más que demostrarme que eres mejor en la cama que muchas chicas que oyen!». La dureza de las palabras acompaña una gestualidad que se torna brutal y no sólo por el énfasis que hay que añadir al usar los signos, sino por intromisión en el espacio de Sarah. Un poco más adelante reclama: «Si aún quieres hablarme aprende a hablar en mi propio idioma». Intuye entonces que ella sabe perfectamente leer los labios, pero entiende su negativa a comunicarse de esa forma no por el respeto que ella señala, sino por una cuestión de control, añadiendo entonces a la discusión: «Ahora soy yo el que controla» y le pide, quizás por última vez, que hable: «iHabla! ¡Habla, háblame!».

La respuesta es quizás ininteligible en principio. El sonido es aterrador. Como espectador que revisita este film una y otra vez, no siento pena, ni lástima; simplemente me veo solo ante un chillido, un grito, que proyecta la situación corporal y relacional de Sarah, como sujeto dominado y discriminado por su condición de sorda. Ese grito nos hace cerrar los ojos (que es justo lo que Leeds hace), aunque no sea una imagen traumática lo que vemos, sino la expresión sonora de la opresión. El grito es en sí violento. El grito es violencia que responde a violencia. Entre lo que se logra articular como audible queda lo siguiente:

«Déjame en paz! ¡No tengo miedo!». 